\section{Rhabdomyolysis associated with cranial diabetes insipidus}

Sir,

I read with interest the recent article by Dr Kung and colleagues ${ }^{1}$ documenting rhabdomyolysis in association with a hypernatraemic hyperosmolal state secondary to cranial diabetes insipidus. We recently reported a patient with rhabdomyolysis and acute renal failure who had developed hypernatraemic hyperosmolality whilst on lithium therapy, presumably as a result of lithiuminduced nephrogenic diabetes insipidus. ${ }^{2}$ These cases serve notice that non-traumatic rhabdomyolysis may occur in hyperosmolal states other than those associated with hyperglycaemia, as previously reported, ${ }^{3,4}$ and consequently that the hyperosmolal state per se predisposes to rhabdomyolysis. However, the cause of rhabdomyolysis in these cases remains uncertain. Concomitant deficiency of potassium and phosphate ions, also recognized predisposing factors for rhabdomyolysis, ${ }^{5}$ may be relevant, but masked by their release from damaged muscle cells. Singhal et al. ${ }^{4}$ found that hyperosmolal diabetic patients developing rhabdomyolysis had lower serum potassium concentrations than those who did not, and we noted relatively low serum potassium and phosphate concentrations in our patient at presentation. ${ }^{2}$ Experimental hypokalaemia has been associated with both reduced transmembrane electrical potential and histological damage in muscle cells, ${ }^{6}$ and similarly intracellular phosphate deficiency can lead to a fall in transmembrane potential since reduced ATP levels will lead to inhibition of the energy-dependent sodium pump. Hence, hypokalaemia and hypophosphataemia may be the significant biochemical derangements leading to muscle cell injury.

Andrew J. Larner The Midland Centre for Neurosurgery \& Neurology, Holly Lane, Smethwick, Warley, West Midlands B67 7JX, UK.

\section{References}

1. Kung, A.W.C., Pun, K.K., Lam, K.S.L. \& Yeung, R.T.T. Rhabdomyolysis associated with cranial diabetes insipidus. Postgrad Med J 1991, 67: 912-913.

2. Bateman, A.M.S., Larner, A.J., McCartney, S.A. \& Rifkin, I.R. Rhabdomyolysis associated with lithium-induced hyperosmolal state. Nephrol Dial Transplant 1991, 6: 203-205.

3. Singhal, P.C. \& Schlondorff, D. Hyperosmolal state associated with rhabdomyolysis. Nephron 1987, 47: 202-204.

4. Singhal, P.C., Abramovici, M. \& Venkatesan, J. Rhabdomyolysis in the hyperosmolal state. Am J Med 1990, 88: 9-12.

5. Gabow, P.A., Kaehny, W.D. \& Kelleher, S.P. The spectrum of rhabdomyolysis. Medicine (Balt) 1982, 61: 141-152.

6. Knochel, J.P. \& Carter, N.W. The role of muscle cell injury in the pathogenesis of acute renal failure after exercise. Kidney Int 1976, 10: S58-S64.

\section{Hyponatraemic encephalopathy complicating thiazide reserpine preparation}

Sir,

We would like to report a case of hyponatraemic encephalopathy due to excessive water drinking in association with a thiazide diuretic.

Our patient was a 54 year old man who was admitted in an acutely confused state. Physical examination revealed no focal neurological deficit. The blood pressure was $130 / 80 \mathrm{mmHg}$ and the pulse rate was $100 / \mathrm{min}$ and regular. He was clinically normovolaemic with a copious urine output of about 3 litres in 12 hours. Blood biochemistry revealed $\mathrm{Na} 114 \mathrm{mmol} / 1, \mathrm{~K} 1.9 \mathrm{mmol} / \mathrm{l}, \mathrm{Cl}$ $79 \mathrm{mmol} / \mathrm{l}$, serum osmolarity $250 \mathrm{mosmol} / \mathrm{kg}$, urine osmolarity $68 \mathrm{mosmol} / \mathrm{kg}$, spot urine $\mathrm{Na} 34 \mathrm{mmol} / \mathrm{l}$, and spot urine $\mathrm{K} 32.1 \mathrm{mmol} / 1$.

A detailed history was obtained from the relatives about 12 hours later. The patient was an anxious individual, who had been taking Adelphane Esidrex on and off for years (one tablet of Adelphane Esidrex consists of $0.1 \mathrm{mg}$ reserpine, $10 \mathrm{mg}$ dihydrallazine sulphate and $10 \mathrm{mg}$ hydrochlorothiazide). He had recently been under great stress from his employer and from his family and combatted his anxiety by drinking about 8 litres of water a day. He also became over-concerned with his health, and insisted on a low salt diet.

The diagnosis was hyponatraemic encephalopathy due to psychogenic polydipsia and thiazide diuretic. He was treated by withdrawing the diuretic and restricting the water intake to $500 \mathrm{ml} /$ day. $100 \mathrm{mmol}$ of $0.9 \% \mathrm{NaCl}$ was given over 1 hour. Over 3 days, the serum sodium rose to $132 \mathrm{mmol} / \mathrm{l}$, and the chloride to $106 \mathrm{mmol} / \mathrm{l}$. He recovered completely.

To our knowledge, there are twelve published cases of hyponatraemic encephalopathy caused by psychogenic polydipsia combined with a thiazide diuretic. ${ }^{1-9}$ However, all these concerned patients who had a specific neurological or psychiatric illness - chronic schizophrenia in 9 patients, epilepsy complicating structural brain disease in 2 patients and psychotic depression in 1 patient. Our patient, however, had no identifiable psychiatric illness, apart from an anxiety-prone personality.

Most reports of thiazide and polydipsia induced hyponatraemia have a favourable outcome, but one reported case involved a 56 year old patient who died due to cerebral oedema with herniation. ${ }^{4}$ Thus clinicians should be alert to hyponatraemia in patients taking thiazides, especially in those at particular risk: e.g. elderly, cirrhotic, and psychiatric patients.

H.Y. Yap

C.P. Lau

Department of Medicine, University of Hong Kong, Queen Mary Hospital, Hong Kong. 